\title{
VEGF-D: a novel biomarker for detection of COVID-19 progression
}

\author{
Yaxian Kong ${ }^{1^{*+}} \mathbb{D}$, Junyan Han ${ }^{1+}$, Xueying $\mathrm{Wu}^{2+}$, Hui Zeng ${ }^{1}$, Jingyuan $\mathrm{Liu}^{3^{*}}$ and Henghui Zhang ${ }^{1^{*}}$
}

As the coronavirus 2019 (COVID-19) continues to spread globally, hundreds of thousands have been infected, among whom approximately 15\% of COVID-19 patients develop severe disease, and 5 to $6 \%$ are critically ill [1]. Critical patients of COVID-19 have a dramatically higher case fatality rate than severe cases. Thus, it is increasingly urgent to develop early and effective predictors to distinguish critical patients from severe patients. Storms of inflammatory cytokines and blood clots were reported to associate with severe disease and fatality of COVID-19 patients [2,3]. We aimed to identify a biomarker for the detection of COVID-19 progression from numerous cytokines and coagulation indicators.

We conducted a retrospective study based on patients with a laboratory-confirmed diagnosis of COVID-19 admitted to the intensive care unit in Beijing Ditan Hospital from January 20, 2020, to March 23, 2020. This study was approved by the Ethics Committee of Beijing Ditan Hospital. The severity of COVID-19 was defined according to the guidelines on the diagnosis and treatment of new coronavirus pneumonia (version 7). All baseline medical record information including demographic, data, complications, and laboratory results were obtained within the first day after hospital admission. Blood samples were collected at baseline and once every 3-7 days during hospitalization. Forty-five cytokines/ chemokines/growth factors in serum were measured using Luminex multiplex assay. Random forests machine learning classifier in Python environment was used for

\footnotetext{
*Correspondence: kongyaxian@ccmu.edu.cn; dtyyicu@ccmu.edu.cn; zhhbao@ccmu.edu.cn

${ }^{+}$Yaxian Kong, Junyan Han and Xueying Wu contributed equally to this work. 'Beijing Key Laboratory of Emerging Infectious Diseases, Institute of

Infectious Diseases, Beijing Ditan Hospital, Capital Medical University, Beijing 100015, China

${ }^{3}$ Intensive Care Medicine, Beijing Ditan Hospital, Capital Medical University, Beijing 100015, China

Full list of author information is available at the end of the article
}

variable importance of the feature rankings. A receiver operating characteristic (ROC) curve was generated to evaluate the diagnostic accuracy of a protein.

A total of 24 COVID-19 patients were enrolled in this study, including $14(58.3 \%)$ severe patients and 10 (41.7\%) critical patients (Table 1). Compared to the severe group, critical cases were of significantly older ages and showed higher white blood cell counts and neutrophil counts. Levels of VEGF-D, TNF- $\alpha$, SCF, LIF, IL-2, IL-4, IL-6, IL-8, IL-10, IL-15, IL-17A, IL-18, IL-1 $\beta$, and IFN- $\gamma$ were significantly higher in the critical group than in the severe group (Table 1). Additionally, lymphocyte count, CRP, LDH, and coagulation indicators (D-dimer, platelet count, PT, and APTT), which were reported to associate with clinical outcome $[4,5]$, were also included in the random forests model.

Strikingly, VEGF-D was identified as the most important indicator related to the severity of COVID-19 (ranked as 1, Fig. 1a). As expected, D-dimer, age, IL-6, and lymphocyte count associated with clinical outcomes of COVID-19 patients reported previously were also highly ranked. VEGF-D had a higher area under the curve (AUC) (0.836 (95\% CI 0.648-1); Fig. 1b) than Ddimer (0.755 (95\% CI 0.527-0.982); Fig. 1c). Consistently, VEGF-D levels were positively correlated with sequential organ failure assessment (SOFA) scores (Fig. 1d). As shown in Fig. 1e, critical patients had higher levels of VEGF-D than the severe cases during the whole course of hospitalization.

To our knowledge, this is the first report of VEGF-D as a potential biomarker for detecting the progression of COVID-19. Despite limited evidence in COVID-19, previous studies demonstrated an important role of VEGF in the pathogenesis of acute lung injury (ALI) and acute respiratory distress syndrome (ARDS) by its properties to increase vascular permeability. Furthermore, VEGF is regarded as an indirect procoagulant for altering the 
Table 1 Demographics, baseline characteristics, cytokines, chemokines, and growth factors of COVID-19 patients

\begin{tabular}{|c|c|c|c|c|}
\hline Characteristics & Total $(n=24)$ & Severe patients $(n=14)$ & Critical patients $(n=10)$ & $P$ values \\
\hline Age mean range, years & $68(36,88)$ & $65(36,81)$ & $77(64,88)$ & .003 \\
\hline Gender & & & & .521 \\
\hline Male, $n(\%)$ & $15(62.5)$ & $10(71.4)$ & $5(50)$ & \\
\hline Female, $n(\%)$ & $9(37.5)$ & $4(28.6)$ & $5(50)$ & \\
\hline Admission to ICU, mean (SD), days & $22(22)$ & $13(8)$ & $35(28)$ & .009 \\
\hline SOFA score, mean (SD) & $3.7(2.4)$ & $2.8(1.7)$ & $4.9(2.8)$ & .015 \\
\hline Complications, n (\%) & & & & .568 \\
\hline Hypertension & $10(41.7)$ & $6(42.9)$ & $4(40.0)$ & 1 \\
\hline Cardiovascular disease & $4(16.7)$ & $1(7.1)$ & $3(30.0)$ & .355 \\
\hline Chronic Pulmonary disease & $6(25)$ & $1(7.1)$ & $5(50.0)$ & .056 \\
\hline Diabetes & $6(25)$ & $2(14.3)$ & $4(40.0)$ & .339 \\
\hline Hyperlipemia & 0 & 0 & 0 & \\
\hline Chronic kidney disease & $3(12.5)$ & $2(14.3)$ & $1(10.0)$ & 1 \\
\hline Immune disorders & $3(12.5)$ & $3(21.4)$ & 0 & .348 \\
\hline Others & $1(4.2)$ & $1(7.1)$ & 0 & 1 \\
\hline \multicolumn{5}{|l|}{ Laboratory data, mean (SD) } \\
\hline WBC, $10^{9} / \mathrm{L}$ & $7.72(5.12)$ & $5.82(2.13)$ & $10.20(6.8)$ & .039 \\
\hline Lymphocyte, $10^{9} / \mathrm{L}$ & $1.08(0.47)$ & $0.93(0.45)$ & $1.27(0.44)$ & .089 \\
\hline Neutrophil, $10^{9} / \mathrm{L}$ & $6.34(4.91)$ & $4.59(1.74)$ & $8.63(6.7)$ & .048 \\
\hline Platelets, $10^{9} / \mathrm{L}$ & $211(98)$ & $206(85)$ & $218(117)$ & .785 \\
\hline PT, s & $13.1(1.7)$ & $13.5(1.9)$ & $12.7(1.4)$ & .291 \\
\hline APTT, s & $33.8(8.6)$ & $33.9(7.2)$ & $33.7(10.4)$ & .973 \\
\hline D-dimer, mg/L & $4.9(7.6)$ & $2.9(5.2)$ & $7.1(9.3)$ & .213 \\
\hline $\mathrm{CRP}, \mathrm{mg} / \mathrm{L}$ & $69.4(66.1)$ & $55.3(32.7)$ & $85.1(89.6)$ & .315 \\
\hline $\mathrm{LDH}, \mathrm{U} / \mathrm{L}$ & $403.6(129.6)$ & $398.3(66.1)$ & $406.3(155.5)$ & .916 \\
\hline Serum creatinine, $\mu \mathrm{mol} / \mathrm{L}$ & $108.1(172.4)$ & $67.9(12.9)$ & $148.1(242.9)$ & .331 \\
\hline$A L T, U / L$ & $40.5(13.9)$ & $44.8(23.2)$ & $41.9(31.5)$ & .809 \\
\hline Blood potassium, $\mathrm{mmol} / \mathrm{L}$ & $4.0(0.5)$ & $3.9(0.4)$ & $4.2(0.5)$ & .299 \\
\hline Blood sodium, mmol/L & $137.4(5.9)$ & $137.1(8.2)$ & $137.8(2.7)$ & .772 \\
\hline \multicolumn{5}{|c|}{ Cytokines, chemokines, and growth factors, median (IQR), pg/mL } \\
\hline VEGF-D & $40.1(17.7,64.8)$ & $25.9(12.3,40.6)$ & $62.9(45.8,79.6)$ & .0048 \\
\hline TNF- $a$ & $25.3(3.2,67.9)$ & $8.6(0,48.4)$ & $54.8(15.3,131.0)$ & .027 \\
\hline SCF & $17.1(9.2,20.7)$ & $13.9(7.7,18.4)$ & $20.1(16.2,68.3)$ & .019 \\
\hline LIF & $18.4(4.2,64.9)$ & $7.4(1.9,21.9)$ & $56.5(10.8,96.9)$ & .0089 \\
\hline IL-2 & $35.2(8.7,59.1)$ & $17.5(4.7,43.5)$ & $55.2(23.5,90.2)$ & .018 \\
\hline IL-4 & $2.1(0,20.2)$ & $0(0,9.8)$ & $143.7(47.2,203.9)$ & .033 \\
\hline IL-6 & $54.2(26.7,157.8)$ & $35.4(19.5,76.9)$ & $143.7(47.2,203.9)$ & .019 \\
\hline IL-8 & $20.1(0.1,44.2)$ & $2.6(0,13.0)$ & $13.0(5.4,17.8)$ & .039 \\
\hline IL-10 & $6.0(1.4,15.3)$ & $3.9(0.9,6.2)$ & $8.4(3.3,24.1)$ & .038 \\
\hline IL-15 & $20.1(4.8,44.2)$ & $10.7(1.8,26.3)$ & $38.7(18.1,83.3)$ & .018 \\
\hline IL-17A & $19.8(0.7,55.3)$ & $9.5(0,26.2)$ & $50.0(16.4,109.4)$ & .021 \\
\hline IL-18 & $86.0(19.8,185.6)$ & $29.2(18.5,109.1)$ & $158.9(91.8,209.2)$ & .046 \\
\hline$I L-1 \beta$ & $8.8(2.1,25.2)$ & $4.4(1.6,15.8)$ & $22.8(7.8,52.7)$ & .022 \\
\hline $\mathrm{IFN}-\gamma$ & $17.6(6.2,29.9)$ & $9.1(3.6,24.2)$ & $26.4(12.9,53.2)$ & .013 \\
\hline
\end{tabular}

WBC white blood cells, CRP C-reactive protein, $L D H$ lactate dehydrogenase, $P T$ prothrombin time, APTT activated partial thromboplastin time, ALT alanine aminotransferase, VEGF vascular endothelial growth factor; TNF- $a$ tumor necrosis factor-alpha, SCF stem cell factor; LIF leukemia inhibitory factor, IL interleukin, IFN interferon 

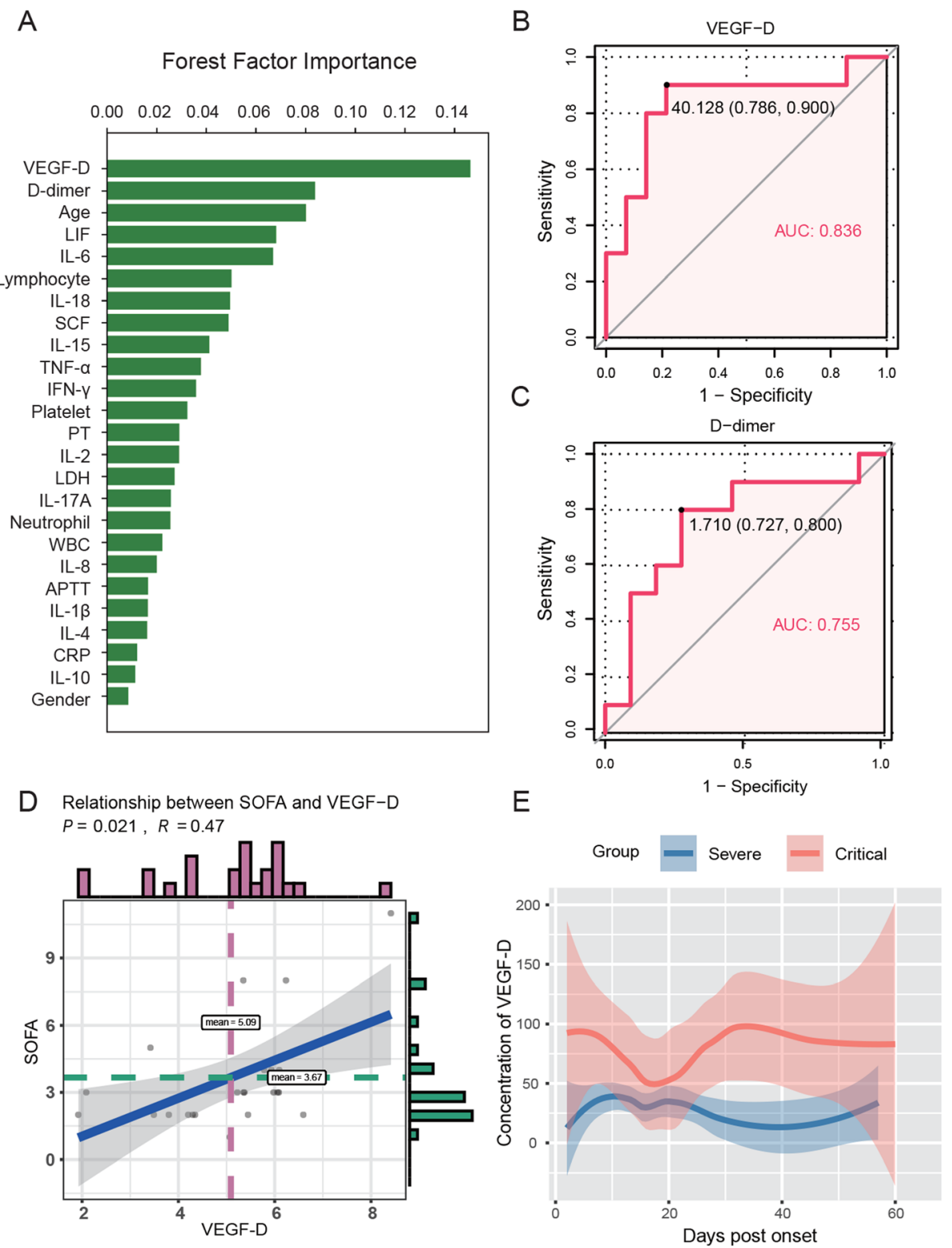

Fig. 1 A high level of VEGF-D predicted progression of COVID-19. a Eleven clinical indicators and 14 cytokines were considered for inclusion and ranked by importance using random forest. b, c Receiver operating characteristic (ROC) analyses for VEGF-D (b) and D-dimer (c) in COVID-19 patients. $\mathbf{d}$ Relationship between VEGF-D and SOFA scores in severe and critical COVID-19 patients was analyzed by the Spearman rank correlation test. e Temporal changes of VEGF-D levels in each group during hospitalization. The median values of each time point (the day from onset) were shown. The $95 \%$ interval was plotted as a colored shadow

hemostatic features of endothelial cells [6]. We hypothesized that elevated VEGF-D level might potentially relate to the storm of blood clots occurring in COVID-19 patients. Notably, it is of great interest to investigate the therapeutic effects of VEGF inhibitor in COVID-19 patients.

This study has limitations, including the small sample size, a single-center experience, and a variable time interval of each patient from admission to symptoms onset. Studies based on a larger cohort in additional sites are needed to verify our findings.

\section{Acknowledgements}

We thank all patients included in this study. We appreciate the works from Dr. Yao Sun from Intensive Care Medicine, Beijing Ditan Hospital; Professor Fujie Zhang, Dr. Di Wang, Dr. Rui Song, and Dr. Yangzi Song from Clinical and Research Center of Infectious Diseases, Beijing Ditan Hospital; and Dr. Mingxi Hua, Dr. Guoli Li, Dr. Juan Du, Dr. Ju Zhang, Kai Han, and Yonghong Yan from Institute of Infectious Diseases, Beijing Ditan Hospital in recruiting 
the patients, extracting the clinical information, and providing technical supports.

\section{Authors' contributions}

YK and $\mathrm{H}$. Zhang designed the study and wrote the manuscript. JL conducted the study and recruited the patients. YK and JH collected the samples, performed the experiments, and analyzed the data. XW analyzed the data and performed the statistical analysis. H. Zeng participated in the critical review of the manuscript. All authors read and approved the final manuscript.

\section{Funding}

This work was supported by the Beijing Municipal Science and Technology Commission (Z201100005420012), Capital Clinical Characteristic Application (Z171100001017052), National Key Sci-Tech Special Project of China (2018ZX10302207), and Beijing Municipal Administration of Hospital Clinical Medicine Development of Special Funding Support (ZYLX201802).

\section{Availability of data and materials}

All data generated or analyzed during this study are included in this published article.

\section{Ethics approval and consent to participate}

This study was approved by the Committee of Ethics at Beijing Ditan Hospital, Capital Medical University, Beijing, China, and each patient gave written informed consent.

\section{Consent for publication}

Not applicable.

\section{Competing interests}

The authors declare that they have no competing interests.

\section{Author details}

'Beijing Key Laboratory of Emerging Infectious Diseases, Institute of Infectious Diseases, Beijing Ditan Hospital, Capital Medical University, Beijing 100015, China. ${ }^{2}$ Immupeutics Medicine Institute, Beijing 100191, China.

${ }^{3}$ Intensive Care Medicine, Beijing Ditan Hospital, Capital Medical University, Beijing 100015, China.

Received: 3 June 2020 Accepted: 8 June 2020

Published online: 23 June 2020

\section{References}

1. Wang D, Hu B, Hu C, Zhu F, Liu X, Zhang J, Wang B, Xiang H, Cheng Z, Xiong Y et al: Clinical characteristics of 138 hospitalized patients with 2019 novel coronavirus-infected pneumonia in Wuhan, China. JAMA. 2020; 323(11):1061-9.

2. Moore JB, June CH. Cytokine release syndrome in severe COVID-19. Science. 2020;368(6490):473-4.

3. Willyard C. Coronavirus blood-clot mystery intensifies. Nature. 2020; 581(7808):250.

4. Wynants L, Van Calster B, Bonten MMJ, Collins GS, Debray TPA, De Vos M, Haller MC, Heinze G, Moons KGM, Riley RD, et al. Prediction models for diagnosis and prognosis of covid-19 infection: systematic review and critical appraisal. BMJ. 2020;369:m1328.

5. Zhang L, Yan X, Fan Q, Liu H, Liu X, Liu Z, Zhang Z: D-dimer levels on admission to predict in-hospital mortality in patients with Covid-19. J Thromb Haemost. 2020;18(6):1324-9.

6. Verheul HM, Hoekman K, Lupu F, Broxterman HJ, van der Valk P, Kakkar AK, Pinedo HM. Platelet and coagulation activation with vascular endothelial growth factor generation in soft tissue sarcomas. Clin Cancer Res. 2000;6(1): $166-71$

\section{Publisher's Note}

Springer Nature remains neutral with regard to jurisdictional claims in published maps and institutional affiliations.

\section{Ready to submit your research? Choose BMC and benefit from:}

- fast, convenient online submission

- thorough peer review by experienced researchers in your field

- rapid publication on acceptance

- support for research data, including large and complex data types

- gold Open Access which fosters wider collaboration and increased citations

- maximum visibility for your research: over $100 \mathrm{M}$ website views per year

At $\mathrm{BMC}$, research is always in progress.

Learn more biomedcentral.com/submissions 